the fourth ventricle. Now, whether subsequent endeavour will reveal there is a communication sometimes or not I do not know. We have taken that into consideration and it would indeed require a different approach, I am sure.

With reference to the discussion about operation versus non-operation, you may recall some years ago we endeavoured to find out the results of operation on patients who were treated in Toronto, and we found out it didn't seem to matter whether you operated or not, there was no statistical difference. Nevertheless, I think that there must be cases when surgical intervention is beneficial, and I think it behoves the medical profession to find out the indications for operation and to operate on that basis. I may say that I have not been impressed by the number of people operated upon in Toronto who were made worse at the time of operation. I have often wondered when they were operated upon, however, if there is not an optimal time for operation and if that had not been missed, perhaps through delay or perhaps it was done too soon. And, I think this matter has to be studied, and it is being studied, starting with experimental animals all over again, repeating the work of Frasier and Allen and others, and endeavouring to start back there now and find out what they can learn from experimental studies.

\title{
PSYCHO-SOCIAL ASPECTS OF SEXUALITY IN SPINAL CORD INJURY PATIENTS
}

\author{
By H. S. Talbot, A.B., M.D., F.A.C.S. \\ Spinal Injuries Centre, V.A. Hospital Roxbery, U.S.A.
}

OF all the problems confronting the spinal cord injury patient, there is none from which it has taken longer to dispel the mists of ignorance than the matter of sexual function. The unwillingness of the medical profession to inform itself on this subject has been incomprehensible and inexcusable. I am sure that mine has been no isolated experience in having known scores of patients who had been solemnly advised that their sex lives were over. Many more had been unable to get any answers at all to their questions. Yet sexuality is an important if not a dominant motive in human life and a sense of sexual adequacy is a major factor in the patient's psycho-social rehabilitation. Nor is there any validity in the complaint that, in the world of today, our sexual preoccupations are too prominent. They are perhaps more readily and openly discussed than was the case 50 to roo years ago. Yet there have been other periods in which sexual customs were more permissive than they are now. For as long as man has left records of his thoughts and feelings he has filled them with references to the same concerns we know today.

It is strange that definitive studies were so late in coming-that the myth of universal impotence persisted so long. The earliest reference to spinal cord injury that has come down to us-the often quoted description from the Smith Papyrus which is dated around the beginning of the fourth millennium B.C.-mentions the presence of erection. Now, at long last, a sufficient number of careful studies have published to render ignorance inexcusable. But it is no longer sufficient to consider only the bare facts of neuromuscular function and the extent of its departure from normal. Sexual function in modern society cannot be simply equated with sexual intercourse. Sexuality may express itself in a variety of forms other than biological activity; the satisfaction, the sense of adequacy which derive from it may be quite independent of voluptuous sensation. In this, as in many other instances, man has transformed a physiological function into a behavioural pattern. We must 
not only know the facts of the neuromuscular deficit, we must understand their implications. We must follow the basic principle of rehabilitation which requires us to concentrate upon what remains and develop its utmost utilisation.

Sexuality comprises three major factors-psychic, gonadal and neuromuscular. Confusion has existed in evaluating the first of these because it has not always been distinguished from perception of somatic stimuli. Loss of the latter is frequent but, in the vast majority of patients, psychosexual content remains substantially normal in spite of its divorce from the soma. Allowing for the distractions of illness, discomfort and fear, which are antagonistic to libidinous impulses in neurologically intact individuals as well, these patients retain the same erotic interests they exhibited before injury.

The gonadal factor may be divided into two components, the hormonal and the germinal. The former also remains unimpaired and powerfully reinforces or may even be partly responsible for the persistence of the psychic element. Secondary sexual characteristics, in both male and female are unaltered. These patients continue not only to think and feel but to look and sound like the men and women they were before. It is a serious misapprehension to disregard this and to consider sexual function in terms only of the germinal activity of the gonads or the neuromuscular component. Our sexual habits and mores and society's recognition of essential maleness or femaleness are largely dependent upon appearance, and if society accepts an individual as a man or a woman, his or her psycho-social adjustment to whatever dysfunction exists is more readily achieved.

Disorder of the germinal function cannot be denied; neither is it adequately understood except when obviously the result of infection in the genital passages. Since it does not occur in the female, it must be attributed to subtle alterations of testicular metabolism. Any explanation will have to account for the fact that testicular atrophy is now far less frequent among these patients than it used to be. The neuromuscular dysfunction has had most of the attention devoted to this subject. If modern investigation has done nothing else, it has demonstrated the grave injustice of imputing impotence categorically to a group of patients of whom two-thirds to three-quarters exhibit erections, and a fair proportion can ejaculate. Studies in females are only fragmentary, but it is reasonable to infer an analogous degree of dysfunction, although it does not interfere with coition or conception.

What we must do, if we are fairly to consider sexual function in these patients, is first to consider the place of sexuality in modern life, generally speaking. Only a very small portion of our libidinous energy and capacity is devoted to procreation. A greater part is expended in the search for gratification along the whole broad spectrum implied by that word. But if we pause for only a moment to consider, we shall recognise that a great part of this gratification is vicarious in naturewhich is to say that it depends upon those elements of sexuality which spinal cord injury patients retain unimpaired. For most of us in the world of today, the greatest part of our libido-derived energy must be diverted into various channels of sublimation, and in this respect the spinal cord injury patient is our equal.

We must continue to study the disturbances of sexual function, in the hope that what we better understand we may be better able to correct. But even as we do so, we must bear in mind that, in this disability as in any other, it is more important to concern ourselves with what is left than with what has gone. We must disabuse not only ourselves, but our profession and the public, of the invidious impression that the patients are sexually impotent and indigent. Their psycho- 
social adjustment to whatever degree of dysfunction they may exhibit will be facilitated by our own better understanding of the subtle and protean role of sexuality in the modern world.

\title{
PROSTIGMIN ASSESSMENT TEST OF FERTILITY IN SPINAL MAN
}

\author{
By Sir Ludwig Guttmann and Dr. J. J. Walsh \\ National Spinal Injuries Centre, Stoke Mandeville Hospital, \\ Aylesbury, England
}

SINCE Spellanzani's observations on the copulative posture of the spinal frog (I 768) the patho-physiology of the sexual function in the spinal man both in animals and man has been a subject of clinical observations and physiological research (Tarchanow, I887; Thorburn, I888; Bernhardt, I888; Wagner \& Stolper, I898; Sherrington, 1906; Riddoch, I91 7; Foerster, 1936). However, it is only during the last 20 years or so that as a result of the greatly increased survival rate of patients with spinal cord injuries, comprehensive studies on potency and fertility in the spinal man have been undertaken. Investigators have employed various procedures to assess potency and fertility in these patients which can be divided into two main groups.

\section{A. Questionnaire and Personal Interview Techniques}

The investigators have, of course, to rely entirely on the statements of the individual by these techniques. Results obtained with these methods, were reported by Bors, in I 948 on I 57 and 1963 on 529 patients, Talbot in I949 on 208 and in 1955 on 408 patients, Zeitlin et al. in 1957 on 100 and Tsuji et al. in I96I on 655 patients. The latter authors stressed the difference between results obtained with the questionnaire technique and personal interview by finding a higher percentage of erections and ejaculations recorded by the personal interview technique. However, there is general agreement amongst all these authors that the percentage of erections 52-94 per cent. were infinitely higher than that of the ejaculations 3-I9.7 per cent. Intercourse possibility was $23-33$ per cent., orgasm 6-I 4 per cent. and reproductive results were the lowest (up to 5 per cent.). Bors (1963) stated that while erection is more frequent with high lesions, ejaculation occurs more often in those with low lesions. This is not, as will be shown later, in accordance with our experience.

\section{B. Direct Examination of the Ejaculate obtained}

I. By Prostatic Massage. This technique was used by Horne, Paul and Munro (1948). These authors found that the amount of ejaculate by prostatic massage could be increased with prior electric rectal stimulation, a method which was previously employed by Dexter, Lerner and Kaplan (I940) and by Joel (I94I). However, Bors and co-workers were not impressed by the results obtained with this method in their own cases which was in accordance with Kuhn's findings (I950). 